\title{
Epigenética, Cuidados Maternais e Vulnerabilidade ao Estresse: Conceitos Básicos e Aplicabilidade
}

\author{
Epigenetics, Maternal Care and Stress Vulnerability: \\ Basic Concepts and Applicability
}

\author{
Grazielle Noro* \& Márcia Cristina Caserta Gon \\ Universidade Estadual de Londrina, Londrina, PR, Brasil
}

\begin{abstract}
Resumo
Cuidados maternais são experiências do início da vida que têm sido consistentemente relacionados com alterações na expressão gênica por meio de mecanismos epigenéticos como a metilação do DNA ou a modificação de suas histonas. O objetivo deste trabalho é apresentar uma investigação teórica sobre cuidados maternais enquanto evento ambiental que pode produzir alterações epigenéticas atuantes na composição da vulnerabilidade ao estresse. A investigação teve por base estudos empíricos e de revisão de literatura com animais não humanos sobre Epigenética, estresse e cuidados maternais. Apresenta também alguns estudos com humanos que mostram tais efeitos, destacando-se aqueles que influenciam ou são influenciados pelo comportamento operante. A partir da investigação realizada encontrou-se que cuidados maternais pós-parto são uma condição ambiental que produz efeitos no eixo hipotálamo-pituitária-adrenal (HPA), participando da composição da vulnerabilidade ao estresse. Seus possíveis efeitos fisiológicos no condicionamento operante sinalizam alternativas para intervenções baseadas na plasticidade da formação do epigenoma. Este conhecimento, além de promover a aproximação entre a Epigenética e a Análise do Comportamento em nível básico por meio de estudos com animais não humanos, poderá contribuir em nível aplicado para um melhor entendimento do neurodesenvolvimento infantil e adequado planejamento de intervenções efetivas com mães e filhos.

Palavras-chave: Cuidados maternais, Epigenética, vulnerabilidade ao estresse, neurodesenvolvimento, Análise do Comportamento.
\end{abstract}

\begin{abstract}
Maternal care is an early life experience that has been consistently related to alterations in the genetic expression through epigenetic mechanisms such as DNA methylation or DNA histone modification. The present study aims to present a theoretical investigation about maternal care as an environmental event that may produce epigenetic alterations related to the biological bases of stress vulnerability. The research was based on empirical studies as well as literature review on non-human animals concerning epigenetics, stress and maternal care. It also presents some studies on humans that show such effects, particularly the ones that influence or are influenced by the operant behavior. Post-natal maternal care is found to cause effects on the hypothalamic-pituitary-adrenal (HPA) axis activity participating in the building of stress vulnerability. Its possible physiological effects on the operant conditioning point out to alternatives to intervention based on the plasticity of the epigenome formation. This knowledge enhances the proximity between Epigenetics and Behavior Analysis at a basic level through studies with non-human animals and at an applied level through a better understanding of child neurodevelopment and proper planning of effective intervention with mothers and children. Keywords: Maternal care, Epigenetics, stress vulnerability, neurodevelopment, Behavior Analysis.
\end{abstract}

O questionamento de como experiências no início da vida influenciam o comportamento adulto é antigo e tem direcionado estudos sobre como sistemas celulares são alterados em interação com o ambiente de maneira que adquiram e mantenham características específicas que

"Endereço para correspondência: R. Prof. Samuel Moura, 367, Londrina, PR, Brasil 86061-060. E-mail: gra.noro@ hotmail.com e marciagon@sercomtel.com.br atuem na fisiologia de uma determinada classe de respostas comportamentais ao longo da vida do indivíduo. Nas últimas décadas, com o avanço da Genética, cientistas têm questionado como células de um determinado organismo, com o mesmo conteúdo genético, podem desenvolver-se de maneira distinta e realizar funções também distintas (Gapp, Woldemichael, Bohacek, \& Mansuy, 2013).

McEwen (2008) afirma que experiências desde a concepção do indivíduo têm profunda influência na 
duração e na qualidade de vida que o mesmo irá ter. O autor também enfatiza o estabelecimento do objetivo científico de se identificar intervenções que sejam mais efetivas no início do desenvolvimento infantil em função das alterações fisiológicas que ocorrem neste período e suas consequências para a saúde física e emocional além do desenvolvimento cognitivo. Hyman (2009) menciona que o estudo de como as experiências do início da vida influenciam o comportamento humano faz-se necessário não somente para o autoconhecimento, mas também para o desenvolvimento de intervenções mais efetivas para o tratamento e possivelmente até a prevenção de transtornos neuropsiquiátricos que produzem significativa carga de sofrimento e incapacitação.

Um número crescente de estudos (e.g. Champagne, 2008; Fagiolini, Jensen, \& Champagne, 2009; Franklin, Saab, \& Mansuy, 2012; Holmes et al., 2005; Muhammad $\&$ Kolb, 2011), tem mostrado que determinados eventos ambientais, especialmente aqueles ocorridos nos primeiros anos de vida, estão consistentemente relacionadas com alterações epigenéticas e podem ser transmitidos para a geração seguinte. Os mecanismos epigenéticos foram definidos por Gudsnuk e Champagne (2011) como alterações moleculares no DNA em si ou nas proteínas as quais o DNA está estreitamente ligado e podem ser induzidas por eventos ambientais. Tais mecanismos são altamente dinâmicos e podem ser influenciados por fatores ambientais tais como dieta, ambientes sociais incluindo-se os ambientes familiares e estresse. A desregulação destes mecanismos tem implicado em distúrbios do neurodesenvolvimento e comportamentos que participam da etiologia de diversas psicopatologias. Determinar a natureza e combinação destes fatores é essencial para entender a relação entre atividade genética e comportamento (Franklin et al., 2012). Descobertas como estas levariam a uma integração mais próxima da genética e a seleção de intervenções farmacológicas, comportamental ou ambas - o que aumentaria a eficácia do tratamento. Além disso, descobertas de como a relação entre o comportamento e o ambiente mudam em função de alterações biológicas proporcionará uma descrição mais completa da psicologia humana (Kennedy, Thompson, \& Caruso, 2001).

Entre as experiências às quais o indivíduo está exposto, em especial nos primeiros anos de vida, estão os cuidados maternais. Estes influenciam de modo persistente alterações epigenéticas e têm sido considerados como importantes determinantes da resistência ou vulnerabilidade da prole a eventos estressores (Beery \& Francis, 2011; Caldji, Diorio, \& Meaney, 2000; Champagne, 2008, 2011; Darnaudéry \& Maccari, 2008; Franklin et al., 2012; Feng et al., 2011; Ros-Simó \& Valverde, 2012). Assim, diferenças em cuidados maternais estão relacionadas com a saúde de seus filhos. Tem-se considerado que este efeito ocorre, pelo menos em parte, mediado pelas influências dos comportamentos de cuidados maternais no desenvolvimento dos sistemas neurais subjacentes a respostas ao estresse ${ }^{1}$, sejam respostas comportamentais ou endócrinas (De Bellis et al., 1994; Caldji et al., 2000; Coplan et al., 1996; Francis \& Meaney, 1999; Franklin et al., 2012; Higley, Haser, Suomi, \& Linnoila, 1991; Holmes et al., 2005; Meaney et al., 1996; Seckl \& Meaney, 1994; Weiss, Pryce, Jongen-Relo, Nanz-Bahr, \& Feldon, 2004).

Por exemplo, estudos (Franklin et al., 2012; Holmes et al., 2005; Weiss et al., 2004) com ratos mostram que cuidados maternais pobres (baixas taxas de respostas de lamber e tocar os filhotes) assim como eventos de separação previsíveis ou não e ocorridos cronicamente influenciaram alterações epigenéticas na prole, modificando a base neurofisiológica da vulnerabilidade a eventos estressores.

O objetivo deste trabalho é apresentar uma investigação teórica sobre cuidados maternais enquanto evento ambiental que pode produzir alterações epigenéticas que atuam sobre a composição da vulnerabilidade ao estresse. Esta teve por base estudos empíricos e de revisão de literatura sobre epigenética, estresse e cuidados maternais, destacando-se pesquisas com não humanos. Apresenta também alguns dados sobre estudos com humanos que mostram tais efeitos, particularmente aqueles que atuam nas bases biológicas do comportamento operante. Para este fim foi realizada um levantamento de estudos empíricos e de revisão a partir das bases eletrônicas PsycINFO, Scopus, Web of Science (acessadas pelo portal CAPES), utilizando-se as palavras-chaves e suas combinações em português "epigenética", "stress / estresse", "cuidados maternais" e sua correspondência em inglês "epigenetics", "stress", "maternal care", sem limites de data. Foram incluídos somente estudos que tratassem de vulnerabilidade ao estresse no período pós-natal, sendo portanto, excluídos os que fizessem referência ao período pré-natal. Foram localizados 72 artigos para análise, sendo 44 estudos empíricos. Após a leitura destes textos, foram procurados outros referenciados na bibliografia de tais artigos para melhor compreensão de seu conteúdo. $\mathrm{O}$ resultado das informações encontradas foi analisado e organizado por meio dos seguintes tópicos: (a) estresse como resposta neurofisiológica; (b) vulnerabilidade ao estresse; (c) cuidados maternais e alterações na vulnerabilidade ao estresse da prole; (d) a atuação dos mecanismos. Para a condução desta investigação será inicialmente apresentado como se dá a resposta neurofisiológica de estresse; a definição de vulnerabilidade ao estresse; cuidados maternais e alterações na vulnerabilidade ao estresse da prole; o que é Epigenética e como atuam seus mecanismos bem como quais os mecanismos especificamente mediadores de alterações na vulnerabilidade ao estresse e decorrentes 
Noro, G. \& Gon, M. C. C. (2015). Epigenética, Cuidados Maternais e Vulnerabilidade ao Estresse: Conceitos Básicos e Aplicabilidade.

de cuidados maternais pós-parto; e, finalmente, considerações sobre Epigenética, plasticidade e intervenções comportamentais.

\section{Estresse como Resposta Neurofisiológica}

Uma definição de estresse diretamente relacionadas à fisiologia foi proposta por Hans Selye no século XIX. Selye (1959) definiu estresse como uma síndrome produzida por vários agentes aversivos. O autor também se referiu ao estresse como uma quebra na homeostase do organismo como também uma resposta comportamental criada por tal desequilíbrio. Herman e Cullinan (1997) referem-se à experiência do estresse como a imposição ou percepção de uma mudança física ou ambiental, podendo ser negativa ou positiva, que elicia um espectro de mudanças fisiológicas que podem ser interpretadas como adaptativas para o organismo. Atualmente, o termo oferece dificuldades de compreensão geradas por sua polivalência, sendo utilizado tanto para designar uma condição, causa ou estímulo desencadeante de uma reação quanto para descrever seu efeito (Jewell \& Mylander, 1988). Neste artigo, usar-se-á a palavra estresse como a resposta neurofisiológica do organismo a eventos estressores, seja ela aguda ou crônica.

A resposta neurofisiológica inicial, em fase aguda, envolve a preparação do organismo para a resposta comportamental de luta-fuga. Com a prolongação ou repetição de eventos estressores, a resposta neurofisiológica é um conjunto de eventos orgânicos que têm como objetivo o reestabelecimento da homeostase ${ }^{2}$.

A quebra da homeostase do organismo é um processo que envolve o eixo neuroendócrino hipotálamo-pituitária-adrenal (HPA) com a produção de hormônios e catecolaminas e pode ocorrer por meio de duas vias neuronais. A primeira, denominada via sistêmica, é estimulada na presença de agentes estressores que podem causar danos fisiológicos sem que haja a necessidade de discriminação deste estímulo como, por exemplo, hipóxia e estímulos cardiovasculares ou imunes. Neste caso, não há estimulação das estruturas centrais superiores (córtex sensoriais, frontal, etc.), mas sim a estimulação direta do núcleo paraventricular do hipotálamo. A partir desse desencadeamento, o processo é o mesmo que ocorre pela via límbica.

${ }^{2}$ Homeostase foi o termo sugerido por Cannon (1939) para designar o esforço dos processos fisiológicos para manterem um estado de equilíbrio interno no organismo. A quebra deste equilíbrio deflagra respostas imediatas e também a longo prazo para promover sua recuperação. As respostas moleculares e comportamentais rápidas que ocorrem por meio de mudanças na função e expressão gênica neuronal constituem uma característica evolutiva importante para o ser humano uma vez que possibilitam o reestabelecimento da homeostasia quando alterações físicas ou ambientais desestruturam este equilíbrio (de Kloet, 2000).
A segunda via, conhecida como via límbica, quando estimulada prepara o organismo para a reação de luta e fuga frente a um estímulo estressor. Primeiramente, o hipocampo é ativado por meio de neurotransmissores provenientes dos córtex sensoriais e frontal, na presença de um estímulo discriminativo aversivo (esta qualidade aversiva do estímulo é aprendida). O hipocampo ativado produz o hormônio corticotrofina (CRH) que estimula a glândula pituitária (hipófise) a produzir o hormônio adrenocorticotrófico (CRTH). Esse último estimula a glândula adrenal (medula e córtex) a produzir as catecolaminas (epinefrina e noraepinefrina) e glicocorticóides ([GCs] cortisol, corticosterona e cortisona; Levine, 2000). As catecolaminas atuam primariamente no Sistema Nervoso Autônomo (SNA) Simpático. Alterações como a dilatação das pupilas, aumento da frequência cardíaca e pressão arterial, dilatação dos brônquios, contração do baço e sudorese são respostas comportamentais que ocorrem para facilitar a reação de luta e fuga (Herman \& Cullinan, 1997).

Durante a resposta de estresse crônica, o organismo, por meio de vários neurotransmissores e hormônios, procura reestabelecer a homeostase do corpo após as tentativas de luta-fuga. Para esta função, os glicocorticóides são produzidos pela medula da glândula suprarrenal. Os glicocorticóides (GCs) atuam especialmente no SNA Simpático. Segundo Salposky (2000), os GCs influenciam no metabolismo celular e geram uma mobilização de substratos energéticos necessários para a produção de respostas fisiológicas adaptativas à presença dos agentes estressores. Os GCs estimulam a síntese de proteínas e glicogênio (gliconeogênese), ativam a lipólise e exercem também várias funções sobre o SNC.

Eventos estressores, quando ocorrem repetidamente, também estão relacionados a mudança nos receptores pós-sinápticos normais de ácido gama-aminobutírico (GABA) principal neurotransmissor inibidor do SNC, levando a superestimulação de neurônios e resultando em irritabilidade do sistema límbico. A presença de GABA diminui a excitabilidade elétrica dos neurônios ao permitir um fluxo maior de íons cloro. A perda de uma das subunidades-chave do receptor GABA prejudica sua capacidade de moderar a atividade neuronal.

Os efeitos do estresse crônico citados na literatura são inúmeros. Entre eles, há as doenças cardiovasculares (aterosclerose, hipertensão arterial, arritmias cardíacas; Newlin \& Levenson, 1982), asma (Von, 2002); doenças dermatológicas (Fried, 2002), doenças bucais (Breivik, Thrane, Murison, \& Gejmo, 1996; Hugoson, Ljunquist, \& Brevik, 2002), redução da libido (Rabin et al., 1990); doenças gástricas (Brasio, 2000); influência como precipitantes de crises epiléticas (Souza, 1996); alterações das secreções de cortisol; supressão do sistema imune (Blalock, Bost, \& Smith, 1985); precipitante de crises do transtorno de personalidade bipolar (Frank, Hlastala, \& Ritenour, 1997), transtorno do pânico e do estresse pós-traumático (EPT; Carvajal, 1995), especialmente, o desamparo aprendido. 


\section{Vulnerabilidade ao Estresse}

Apesar da ocorrência aleatória de eventos estressores durante a vida de todos os seres humanos, a vulnerabilidade da pessoa a tais eventos foi definida por Jewell e Mylander (1988) como uma tendência a reagir de modo intenso, por meio de reações psicológicas e físicas, a situações estressantes, com etiologia multifatorial e desenvolve-se diferentemente em cada indivíduo. A vulnerabilidade ao estresse como resposta neurofisiológica pode ser compreendida, portanto, como um determinado funcionamento orgânico em que as estruturas, hormônios e neurotransmissores apresentam-se hiperativadas ou mais rapidamente ativadas quando comparado ao funcionamento orgânico de indivíduos considerados não vulneráveis, ou seja, resilientes ao estresse. Entre os fatores que influenciam a composição da vulnerabilidade ao estresse, encontra-se o gênero sexual (Calais, Andrade, \& Lipp, 2003); estresse maternal pré-natal (Lee, Brady, Shapiro, Dorsa, \& Koenig, 2007); as práticas parentais (Luthar \& Ziegler, 1991); as cognições (Rangé, 2001). Estudos recentes têm adicionado fatores contribuintes da composição da vulnerabilidade ao estresse ao mostrar que cuidados maternais pós-parto alteram as bases neurofisiológicas da resposta a eventos estressores.

\section{Cuidados Maternais e Alterações na Vulnerabilidade ao Estresse da Prole}

Com roedores, assim como com a maioria dos mamíferos, o período pós-parto é caracterizado por comportamentos de cuidados da mãe com a cria. Os estudos realizados nessa área têm avaliado as diferenças naturais de cuidados maternais especialmente com ratos Long Evans (Meaney, 2001). Durante a primeira semana pós-parto, as ratas mães emitem respostas de "lamber" (licking) e "tocar" (grooming; LG) especialmente durante os períodos de amamentação em posição com a coluna arqueada (arched back nursing [ABN]; Champagne, 2008; Francis \& Meaney, 1999). Tais respostas comportamentais podem ser mensuradas em frequência e compõem o que se conhece como cuidados maternais. Servem para estimular os filhotes, modificar a temperatura do corpo e cérebro e induzem a produção de água e sal para atender as necessidades fisiológicas da lactação (Gubernick \& Alberts, 1983). Ratas parideiras apresentam variações naturais de comportamentos maternais. As ratas parideiras observadas durante os dias um e seis pós-parto são classificadas quanto às taxas de LG-ABN em altas, médias e baixas (Champagne, 2008; Franklin et al., 2012; Holmes et al., 2005).“Mães boas" apresentam altos níveis de cuidados maternais ativos como lamber e tocar (LG), amamentação com a coluna arqueada e construção do ninho. "Mães deficientes" apresentam baixos níveis dos comportamentos descritos. Os comportamentos maternais são fundamentais para a vulnerabilidade ou resiliência ao estresse durante a vida adulta.

\section{Efeitos Neurofisiológicos na Resposta de Estresse na Prole de Ratas que Apresentam Altas e Baixas Taxas de LG-ABN}

Os estudos para a avaliação dos efeitos neurofisiológica na prole de ratas que apresentam altas e baixas taxas de LG-ABN utilizam paradigmas como a manipulação precoce; a separação ou privação maternal previsível ou não previsível; e, a observação comparativa entre ratas parideiras que apresentam baixas e altas taxas de LG-ABN Neste último paradigma, os filhotes são separados de suas mães biológicas e reunidos a mães adotivas. Para prevenir alterações no comportamento maternal por mudanças na prole, somente dois entre os 10 filhotes da cada mãe são adotados. Quatro grupos experimentais são formados: $\mathrm{H}-\mathrm{H}^{0}$ (mãe com altas taxas de LG recebe filhos de outra

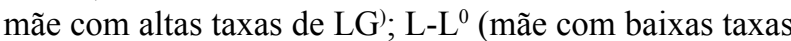
de $L G$ recebe filhos de outra mãe com baixas taxas de LG); L-H (mãe com baixas taxas de LG recebe filhos de mãe com altas taxas de LG); H-L (mãe com alta LG recebe filhos de mãe com baixa LG; Figura 1). Filhotes cuidados por mães com altas taxas de LG apresentam menor vulnerabilidade ao estresse em testes neurofisiológicos e comportamentais, ainda que nascidos de mães com baixas taxas de LG (Caldji et al., 2000).

Em alguns estudos, os experimentos foram continuados com as gerações seguintes. Os resultados mostraram que ratas fêmeas filhas de mães biológicas com baixas taxas de LG e cuidadas por parideiras com altas taxas de LG apresentaram altas taxas de LG no período pós-natal de seus próprios filhos (Caldji et al., 2000), o que confirma não só a alteração genômica ocorrida com os sujeitos adotados, mas também sua transmissão para a geração vindoura.

Os efeitos neurofisiológicos de tais experimentos mostram alterações na atividade do eixo HPA (hipotálamo-pituitária-adrenal) servindo assim como correlatos para as respostas comportamentais a eventos estressores. Para elucidar as mudanças neurais subjacentes aos efeitos de cuidados maternais pós-parto, pesquisadores avaliam os níveis de fator liberador de corticotrofina (CRF) relacionado com a mediação da emoção e dos distúrbios relacionados ao estresse, assim como os níveis de corticosterona, receptores de GRs e receptores de GABA. Os efeitos descritos a seguir estão direta ou indiretamente relacionados com a hipo ou hiperativação do eixo HPA.

O CRF é liberado a partir do núcleo paraventricular hipotalâmico controla a ativação do eixo HPA. Um estudo realizado por Caldji et al. (2000) mostrou que os filhotes das ratas com altas taxas de LG apresentaram taxas plasmáticas reduzidas de hormônio corticotrópico e corticosterona como respostas a eventos estressores e níveis reduzidos de CRF hipotalâmica (Caldji et al., 2000). Portanto, a atividade do eixo HPA foi mais modesta nos filhos de ratas com altas taxas de LG. Há consistente evidência de que há o aumento de transmissões de CRF em ratos submetidos a experiências de trauma ou negligência nos primeiros anos de vida (Holmes et al., 2005; Lyons et al., 2010; Lyons, Yang, Mobley, Nickerson, \& Schatzberg, 2000). 
Noro, G. \& Gon, M. C. C. (2015). Epigenética, Cuidados Maternais e Vulnerabilidade ao Estresse: Conceitos Básicos e Aplicabilidade.

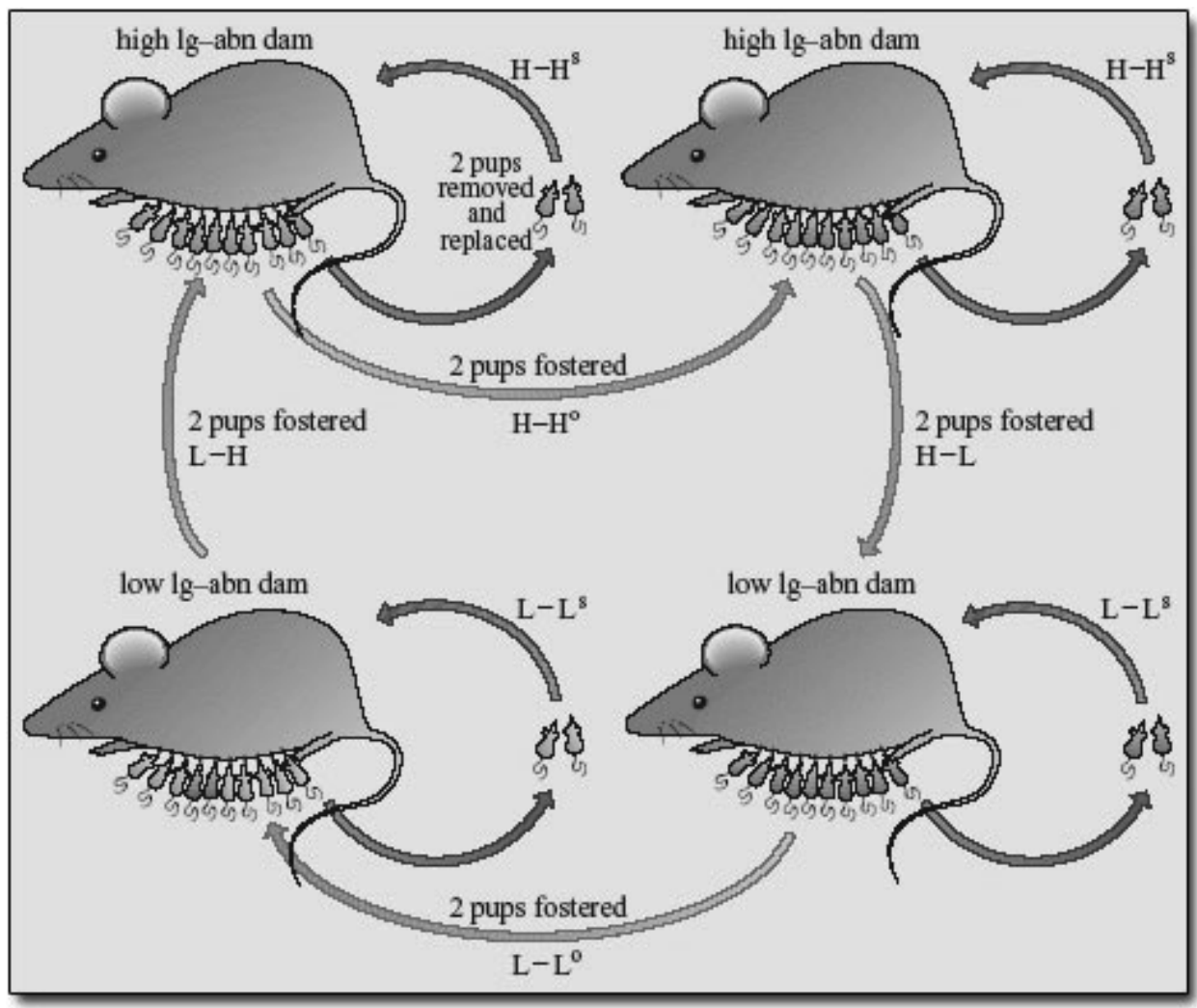

Figura 1. Adoção cruzada entre parideiras com altas e baixas taxas de LG-ABN. Recuperado em http://www.open.edu/openlearnworks/mod/page/view.php?id=45783\#FIG003_009

Outra alteração neurofisiológica observada nos filhotes de ratas com altas taxas de LG foi o funcionamento do sistema GABAérgico no neurodesenvolvimento de seu córtex frontal. Houve aumento das taxas de receptores de GABA, especialmente nos neurônios da amídala e locus coeruleus (Caldji et al., 2000). O ácido amino-butírico é um neurotransmissor inibitório que age no sistema nervoso central, e quando ligado a seus receptores específicos, provoca a abertura de um canal por onde entram íons cloreto na célula neuronal, fazendo com que a célula fique hiperpolarizada e assim, dificultando a despolarização. Como consequência, dá-se a diminuição da condução neuronal, provocando a inibição do SNC. Os estudos também mostraram altas taxas de ativadores de receptores GABA como e de receptores benzodiazepínicos, o que auxilia na hipoativação do eixo HPA, ou seja, facilitando assim o reequilíbrio orgânico pela homeostase (Caldji et al., 2000). Assim, a resposta de estresse apresenta-se atenuada, ou seja, mais resiliente conforme corroborado no mesmo estudo por meio dos testes comportamentais, cujos resultados foram taxas mais baixas de "respostas de medo" frente a eventos estressores (exploração de novos ambientes) se comparados a quaisquer uns dos grupos controle (Caldji et al., 2000).

As ações do CRF são reguladas por receptores de glicocorticóides (GRs) localizados no hipocampo. Também se observou que os níveis de mensageiros receptores hipocampais de glicocorticóides aumentaram em filhotes de ratas com altas taxas de LG-ABN, como também a sensibilidade para feedback negativo para glicocorticóides (Caldji et al., 2000; Champagne, 2008). Há evidências que mostram que os GRs do hipocampo em filhotes de ratas com baixas taxas de LG-ABN são incapazes de regular o eixo HPA em função de sua expressão reduzida (Huot, Gonzalez, Ladd, Thrivikraman, \& Plotsky, 2004). Estudos mostraram que a manipulação precoce favorece o rápido retorno a linha de base de GCs (Meaney et al., 1996). Tal resposta, por ser rápida, minimiza o risco de prejuízo ao sistema nervoso devido a exposição prolongada a glicocorticóides.

Os resultados de análises nos cérebros de ninhadas de mães com baixas taxas de LG-ABN mostraram taxas elevadas de receptores de CRF - o que contribui para a ativação do eixo HPA. Os receptores benzodiazepínicos - potencializadores dos efeitos inibidores do neurotransmissor GABA, como também os receptores de GABA na amígdala e locus coerelus foram avaliados com taxas reduzidas nas mesmas ninhadas (Caldji et al., 2000). Este efeito contribui para evitar a inibição do eixo HPA.

Em outros estudos, foram encontradas, nas análises com filhotes de ratas com baixas taxas de LG-ABN, taxas elevadas de ácido ribonucleico (RNA) mensageiro (mRNA) para a produção de fator neurotrófico derivado do cérebro (BDNF) na região hipocampal e taxas igualmente elevadas de mRNA para a produção de CRF na amígdala. Neurônios liberadores de CRF projetam-se do núcleo central da amígdala e liberam noradrenalina para 
regiões como o locus coerulus, iniciando a ativação neuronal nesta região (Caldji et al., 2000; Gray \& Bingaman, 1996; Koegler-Muly, Owens, Ervin, Kilts, \& Nemeroff, 1993; Lavicky \& Dunn, 1993; Valentino, Curtis, Page, Pavcovich, \& Florin-Lechner, 1998)

Outras evidências dos efeitos de baixas taxas de LG-ABN em ratos durante o período pós-natal são taxas reduzidas de sobrevivência e elevadas taxas de apoptose neuronal no hipocampo; taxas reduzidas de fator de crescimento de fibroblastos; alterações na liberação de dopamina associada a resposta de estresse; e anormalidades neuronais no córtex pré-frontal (PFC; Caldji et al., 2000).

\section{Epigenética}

A experiência de cuidados maternais pós-parto tem, claramente, efeitos duradouros na neurobiologia e com- portamento. Entretanto, permanece o questionamento de como estas experiências ocorridas na infância têm efeitos a longo prazo, ou seja, durante a vida adulta, sendo inclusive transmitidas para gerações seguintes. Esta pergunta tem sido respondida através da elucidação dos mecanismos epigenéticos observados em recentes estudos.

Segundo Franklin et al. (2012), alterações epigenéticas são processos que induzem mudanças na expressão do gene e que são herdadas sem alterar a sequência das bases nitrogenadas do DNA (ácido desoxirribonucleico). A Epigenética constitui, portanto, uma área de conhecimento que tem os objetivos de investigar e responder questões sobre como modificações químicas (por exemplo, metilação, acetilação, fosforilação, entre outras) nos nucleotídeos e histonas do DNA que constitui os genes ocorrem ao longo do tempo em função de experiências ambientais e são transmitidas para gerações seguintes.
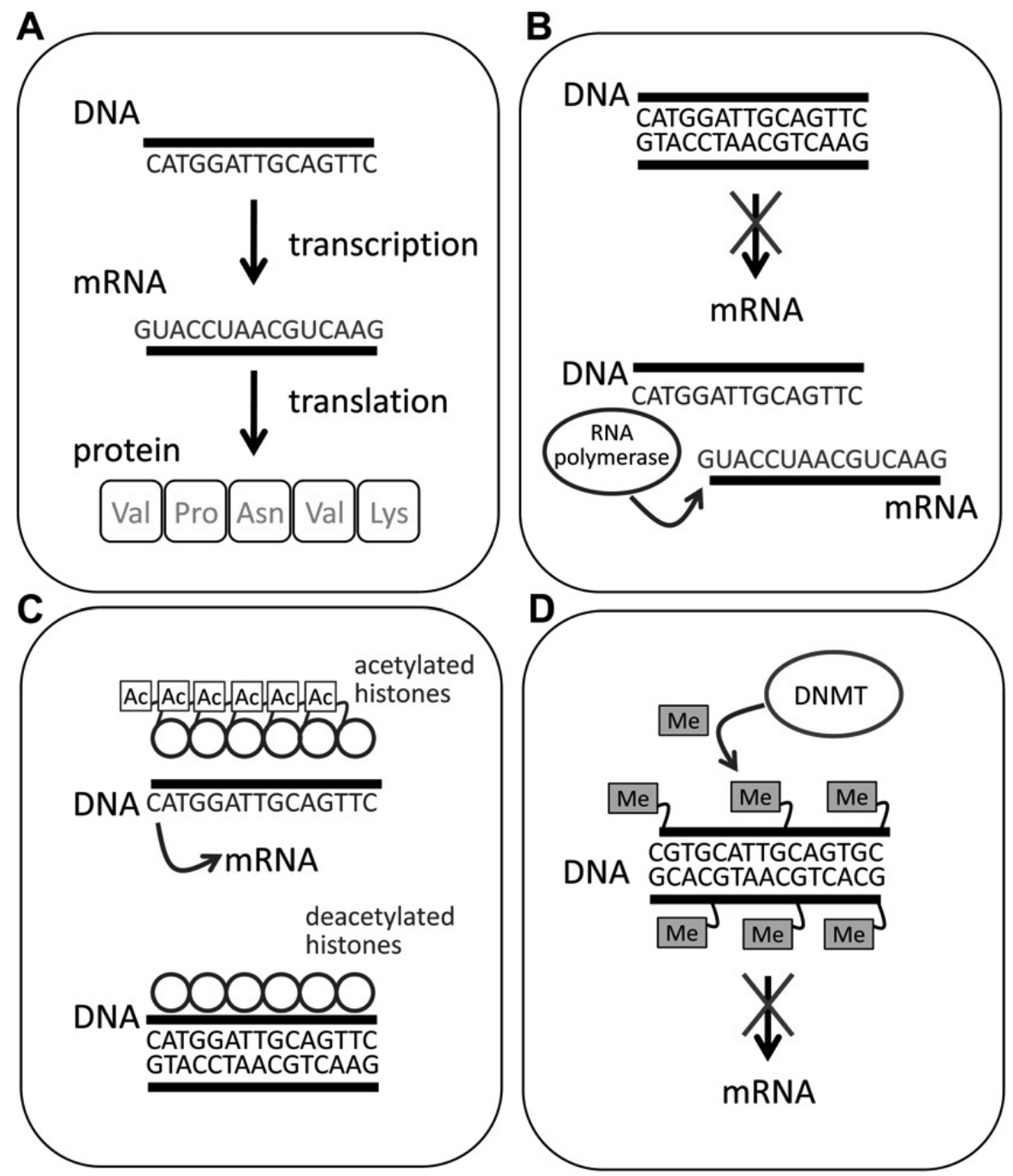

Figura 2. Regulação do gene e mecanismos epigenéticos (Gudsnuk \& Champagne, 2011, p. 705).

O DNA está estocado no núcleo celular de forma altamente compacta. Para que os genes tenham impacto biológico, os mesmo devem ser expressados. A expres- são gênica envolve a transcrição do DNA para um RNA mensageiro e então, a tradução deste para a formação de uma proteína (Figura 2A). A transcrição do DNA é um 
Noro, G. \& Gon, M. C. C. (2015). Epigenética, Cuidados Maternais e Vulnerabilidade ao Estresse: Conceitos Básicos e Aplicabilidade.

processo muito elegante, e o tempo e nível de expressão do gene são fundamentais para o processo normal de desenvolvimento (Gudsnuk \& Champagne, 2011). A atividade do gene é determinada pelo nível de transcrição do DNA par o RNA mensageiro (RNAm), conforme apresentado na Figura 2A . O processo de tradução envolve o uso de RNAm para gerar uma proteína, que consiste em uma sucessão de aminoácidos. Na figura 2B, o DNA está compactado (acima), e assim, há uma supressão da expressão do gene (ou seja, o RNA não é produzido). Quando o DNA está menos compacto (abaixo), enzimas como a RNA polimerase podem ligar-se ao DNA e iniciar o processo de transcrição.

Dentro do núcleo celular, o DNA está envolto por proteínas histonas, que permitem a compactação do material genético. Para que a ativação ou expressão dos genes seja possível, o DNA deve ser liberado desta estrutura densa e tornar-se acessível a fatores de transcrição e outras enzimas, como a RNA polimerase, que inicia o processo de transcrição (Figura 2B). Uma maneira de atingir este resultado é modificar as proteínas histonas de maneira que elas tornem-se menos atraídas pelo DNA. As modificações epigenéticas ocorrem nas partes "caudais" de duas histonas interligadas e podem ocorrer por acetilação - adição do grupo acetil (-CH3CO); deacetilacão - remoção do grupo acetil (Figura 2C), metilação - adição do grupo metil (-CH3); fosforilação - adição do grupo fosfato (-PO4); ou ainda, ubiquitinação - marcação da histona por uma proteína chamada ubiquitina para que tal proteína seja degradada. A adição ou remoção de estruturas químicas as partes caudais das histonas alteram sua interação com o DNA. Por exemplo, a acetilação de histonas, ou seja, a adição de um grupo acetil (Ac) às proteínas histonas esquematizada na Figura $2 \mathrm{C}$, pode relaxar a interação (acima) entre histonas e DNA e assim, aumentar o nível de transcrição gênica - processo que resulta em aumentada expressão do gene em função de uma interação fraca, mais solta entre histonas e DNA. Ao contrário, a remoção do grupo acetil das partes caudais da histona (deacetilação) - Figura 2D permitirá que as mesmas tornem-se firmemente ligadas ao DNA. Assim, expressão do gene (abaixo) é reduzida devido a esta interação mais forte e intensa entre DNA e histona, o que por sua vez, dificulta o acesso da enzima RNA polimerase.

Outro mecanismo epigenético de significativa importância é a metilação - processo químico que constitui na adição do grupo metil (-CH3) à base nitrogenada citosina (participante da região regulatória da expressão gênica) do DNA resultando em um composto chamado 5-metilcitosina (Razin, 1998; Turner, 2001; Figura 2D). Esta ligação entre o grupo metil e a citosina é uma alteração estável e duradoura, mas reversível (Champagne, 2008).

Como no caso da modificação de histonas, a adição de grupos metis ao DNA torna o mesmo altamente compacto e, portanto, menos acessível para a transcrição pela mRNA por meio da enzima RNA polimerase. Esta alteração resulta na inibição ou em uma atividade genética aumentada do DNA (Dudley, Li, Kobor, Kippin, \& Bredy, 2011). Baixos níveis de metilação resultam na ativação aumentada do DNA, e assim com a ativação de genes que promovem o crescimento celular, a instabilidade cromossômica, e a perda de imprinting- fenômeno no qual certos genes são expressos apenas por um alelo, enquanto o outro é metilado (inativado). Altos níveis de metilação, por outro lado, promovem a inibição do DNA, o que resulta em baixo crescimento celular, reparação do DNA danificado e iniciação do processo de apoptose (morte celular). As metilações do DNA são mantidas após a divisão celular e então, passadas da célula mãe para a célula filha, sendo esta de modificação epigenética que determinará a diferenciação celular (Jones \& Taylor, 1980).

\section{Mecanismos Epigenéticos Mediadores de Alterações na Vulnerabilidade ao Estresse Decorrentes de Cuidados Maternais Pós-Parto}

\section{Modificações nos Genes Promotores de GRs}

Altas taxas de metilação do DNA, modificação de histonas e não codificação de RNAs nos genes promotores de GRs foram encontradas nos filhotes de parideiras com baixas taxas de LG-ABN (Champagne, 2008; Gudsnuk \& Champagne, 2011; Holmes et al., 2005; Hyman, 2009; McEwen, 2008). Conforme exposto anteriormente, devido à presença do grupo metil no DNA, o acesso ao mesmo para o processo de transcrição a partir do RNA é reduzido e assim, não há decodificação do mesmo. Desta maneira, há o "silenciamento" do gene NR3C1 (regulador da produção de GRs; Hyman, 2009). Filhotes de parideiras com baixas taxas de LG-ABN também apresentaram altas taxas de modificação de histonas no DNA dos genes promotores de GRs por meio de processos deacetilação (Champagne, 2008; Holmes et al., 2005; Weaver et al., 2004). Como os GRs não são produzidos, há um aumento na transmissão de CRF e consequente aumento na ativação do eixo HPA.

\section{Modificações nos Genes Promotores de Receptores de GABA e Receptores Benzodiazepínicos}

No hipocampo de filhotes de parideiras com baixas taxas de LG-ABN foram encontrados níveis reduzidos de ácido glutâmico e descarboxilase (GAD1), enzima sintetizadora de GABA. Análises da região do gene promotora de GAD1 sugerem que o comportamento LG-ABN das mães induz uma redução na metilação do DNA e também um aumento na acetilação de histonas nesta região (Gudsnuk \& Champagne, 2011).

Resultados similares foram encontrados no hipocampo de vítimas de suicídio que apresentavam histórico de abuso infantil. Foram encontrados baixos níveis de mRNA nos receptores de glicocorticóides, assim como um aumento na metilação da citosina em um promotor de receptores de um determinado glicocorticóide - o NR3C1 (McGowan et al., 2009). 


\section{Epigenética, Comportamento Operante e Plasticidade em humanos}

As contribuições da Epigenética reforçam não só a influência das bases fisiológicas no comportamento como também a importância de intervenções que promovam alterações ambientais saudáveis, pela durabilidade e profundidade de seus efeitos. Ainda que a aprendizagem (ontogênica e cultural) possa ensinar o indivíduo a lidar com eventos estressores de maneira adequada, há componentes neurobiológicos que são alterados pela experiência e são a base para as respostas comportamentais. A influência do ambiente no neurodesenvolvimento é de significante importância para humanos, pois, como visto, estabelece o epigenoma, que como tal, é participante do das respostas comportamentais do indivíduo.

A influência do ambiente no estado dos genes tem sido estudada desse o século XVIII. Alguns estudiosos a contribuir para a compreensão de tais mecanismos foram Caspar Friederich Wolff (1734 - 1793), como também os lamarckistas epigeneticistas, entre os quais, Le Dantec (1869 - 1917), em seu Traité de Biologie (1903). Também Jean Piaget (1896 - 1980) propôs a Epistemologia Genética com base na influência do ambiente no estado dos genes (1970). Burrhus Frederic Skinner (1904 - 1990) foi outro pesquisador a estudar extensivamente a influência do ambiente no estado dos genes ao propor o condicionamento operante. Skinner (1989) apontou o reforçamento ocorrido durante a vida do indivíduo como participante das alterações do estado do cérebro. Além disso, também apontou para as suscetibilidades para o reforçamento e sua relação com o comportamento operante, o que sugere diferenças genéticas individuais não estabelecidas pela seleção natural, mas ainda assim propagadas de uma geração a outra.

Um número significativo de estudos empíricos com humanos, utilizando marcadores biológicos mostram os efeitos do comportamento operante na expressão gênica. Um exemplo da alteração ocorrida na circuitaria cerebral do sistema de recompensa após condicionamento operante da resposta obtenção de comida foi apresentado na pesquisa de Guegan et al. (2013). O estudo mostrou alterações na densidade dos dendritos dos neurônios no nucleus accumbens após condicionamento operante de ingestão de alimentos de alto valor calórico. A alteração no valor hedônico da ingestão de alimentos sugere possíveis causas para as altas taxas de obesidade encontradas especialmente em países desenvolvidos. Segundo Herrera, Keildson e Lindgren (2011), ocorrem alterações epigenéticas que determinam o valor hedônico da ingestão de alimentos e, portanto, são encontradas nas gerações subsequentes.

Outro exemplo é o efeito do comportamento operante se exercitar sobre o fluxo sanguíneo no córtex pré-frontal e no aumento do hipocampo, melhorando a capacidade de decisão e auto-controle em casos de transtornos de ansiedade e depressão em que as áreas cerebrais mencionadas são menos eficientes (Erickson et al., 2011). Getz, Kirkengen e Ulvestad (2011) e McEwen e Getz (2013) afirmam que modificações estruturais no cérebro têm sido associadas com a psicoterapia bem-sucedida. Neste sentido, Stahl (2012) argumenta que a psicoterapia pode ser considerada uma "intervenção epigenética", juntamente com a terapia farmacológica. O enriquecimento ambiental é um exemplo de foco terapêutico que apresenta implicações diretas no desenvolvimento neurobiológico (Li \& Tang, 2005). Em seu experimento, tais autores demonstraram a restauração do fator neurotrófico derivado do cérebro em ratos que apresentavam Doença de Huntington assim como, em ratos apresentando a Doença de Alzheimer, foi observada a elevação dos níveis de enzimas Neprilysin - enzima cuja ação é reconhecida por atenuar os sintomas da doença de Alzheimer (El-Amouri et al., 2008).

\section{Implicações para Possíveis Intervenções em Neurodesenvolvimento Infantil}

Um possível foco terapêutico na intervenção com mãe e filhos poderia ser a sensibilização parental a sinais emitidos pela criança assim como um aumento no contato entre cuidador e criança (Kaplan, Evans, \& Monk, 2008). $\mathrm{O}$ estudo mostrou altos níveis de variabilidade da taxa de batimentos cardíacos em situações de repouso, baixos níveis de reatividade cardíaca e de cortisol em situações de estresse moderado em crianças cujas cuidadoras foram previamente consideradas como "sensíveis", ou seja, com escores abaixo da média da classificação de depressão ou transtornos de ansiedade. Tais resultados são consistentes com boa saúde emocional. Um outro estudo, realizado na Romênia, avaliou crianças em orfanatos antes e após sua estada de 14 meses com pais adotivos. Os resultados mostraram que todas as meninas adotadas apresentaram menores taxas de doenças psiquiátricas e todas as crianças apresentaram menores chances de desenvolvimento futuro de tais doenças (McLaughlin, Nelson, Fox, \& Zeanah, 2012). Ambos os estudos apontam para intervenções que favoreçam a relação entre cuidador e filho.

Segundo Gudsnuk e Champagne (2011), a plasticidade epigenética não está limitada à intervenção farmacológica e as mudanças em perfis epigenéticos ao longo do tempo e em resposta a experiências ao longo da vida são de grande interesse em estudos com humanos e animais não humanos. Assim também, as intervenções comportamentais e práticas preventivas também se beneficiam das descobertas em Epigenética a respeito da vulnerabilidade ao estresse, por alertar e direcionar indivíduos para a construção de ambientes que promovam o neurodesenvolvimento da criança resiliente ao estresse.

\section{Referências}

Beery, A. K., \& Francis, D. D. (2011). Adaptive significance of natural variations in maternal care in rats: A translational perspective. Neuroscience and Biobehavioral Reviews, 35, 1552-1561. doi:10.1016/j.neubiorev.2011.03.012 
Noro, G. \& Gon, M. C. C. (2015). Epigenética, Cuidados Maternais e Vulnerabilidade ao Estresse: Conceitos Básicos e Aplicabilidade.

Blalock, J. E., Bost, K. L., \& Smith, E. M. (1985). Neuroendocrine peptide hormones and their receptor in the immune system: Production, processing and action. Journal of Neuroimmunology, 10(1), 31-40. doi:10.1016/01655728(85)90032-3

Brasio, K. M. (2000). Eficácia do treino de controle de stress na retocoliteulcerative inespecifica (Tese de doutorado, Pontifícia Universidade Católica de Campinas, SP, Brasil).

Breivik, T., Thrane, P. S., Murison, R., \& Gemo, P. (1996). Emotional stress effects on immunity, gingivitis and periodontitis. European Journal of Oral Sciences, 104, 327 334. doi:10.1111/j.1600-0722.1996.tb00087.x

Calais, S. L., Andrade, L. M. B., \& Lipp, M. E. N. (2003). Diferenças de sexo e escolaridade na manifestação de stress em adultos jovens. Psicologia: Reflexão \& Crítica, 16(2), 257-263. doi:10.1590/s0102-79722003000200005

Caldji, C., Diorio, J., \& Meaney, M. J. (2000). Variations in maternal care regulate the development of stress reactivity. Biological Psychiatry, 48, 1164-1174. doi:10.1016/s00063223(00)01084-2

Cannon, W. B. (1939). The wisdom of the body. New York: Norton.

Carvajal, A. C. (1995). Mecanismos psicogênicos y biológicos do stress agudo y crônico. Revista Psiquiátria Clínica de Santiago do Chile, 32(12), 37-48.

Champagne, F. A. (2008). Epigenetic mechanisms and the transgenerational effects of maternal care. Frontiers in Neuroendocrinology, 29, 386-397. doi:10.1016/j. yfrne.2008.03.003

Champagne, F. A. (2011). Maternal imprints and the origins of variation. Hormones and Behavior, 60, 4-11. doi:10.1016/j. yhbeh.2011.02.016

Coplan, J. D., Andrews, M. W., Rosenblum, L. A., Owens, M. J., Friedman, S., Gorman, J. M., \& Nemeroff C. B. (1996). Persistent elevations of cerebrospinal fluid concentrations of corticotropin-releasing factor in adult nonhuman primates exposed to early-life stressors: Implications for the pathophysiology of mood and anxiety disorders. Proceedings of the National Academy of Sciences of the USA, 93(4), 1619-1623. doi:10.1073/pnas.93.4.1619

Darnaudéry, M., \& Maccari, S. (2008). Epigenetic programming of the stress response in male and female rats by prenatal restraint stress. Brain Research Rewies, 57, 571-585. doi:10.1016/j.brainresrev.2007.11.004

De Bellis, M. D., Chrousos, G. P., Dorn, L. D., Burke, L., Helmers, K., Kling, M. A, ...Putnam, F. W. (1994). Hypothalamicpituitary-adrenal axis dysregulation in sexually abused girls. Journal of Clinical Endocrinology and Metabolism, 78(2), 249-255. doi:10.1210/jcem.78.2.8106608

De Kloet, E. R. (2000). Stress in the brain. European Journal of Pharmacology, 405, 87-198. doi:10.1016/s00142999(00)00552-5

Dudley, K. J., Li, X., Kobor, M. S., Kippin, T. E., \& Bredy, T. W. (2011). Epigenetic mechanisms mediating vulnerability and resilience to psychiatric disorders. Neuroscience and Biobehavioral Reviews, 35(7), 1544-1551. doi:10.1016/j. neubiorev.2010.12.016

El-Amouri, S. S., Hong, Z., Jin, Y., Robert, M., Inder, M. V., \& Kindy, M. S. (2008). Neprilysin: An enzyme candidate to slow the progression of Alzheimer's disease. The American Journal of Pathology, 172(5), 1342-1354. doi:10.2353/ ajpath.2008.070620
Erickson, K. I., Voss, M. W., Prakash, R. S., Basak, C., Szabo, A., \& Chaddock, L. (2011). Exercise training increases size of hippocampus and improves memory. Proceedings of the National Academy of Sciences of the United States of America, 108(7), 3017-3022. doi:10.1073/pnas.1015950108

Fagiolini, M., Jensen, C. L., \& Champagne, F. A. (2009). Epigenetic influences on brain development and plasticity. Current Opinion in Neurobiology, 19, 207-212. doi:10.1016/j. conb.2009.05.009

Feng, X., Wang, L., Shangchuan, Y., Dongdong, Q., Wang, J., Chunlu, L., ...Xintian, H. (2011). Maternal separation produces lasting changes in cortisol and behavior in rhesus monkeys. Proceedings of the National Academy of Sciences of the United States of America, 108(34), 14312-14317. doi:10.1073/pnas.1010943108

Francis, D. D., \& Meaney, M. J. (1999). Maternal care and the development of stress responses. Current Opinion in $\mathrm{Neu}$ robiology, 9, 128-134. doi:10.1016/s0959-4388(99)80016-6

Frank, E., Hlastala, S., \& Ritenour, A. (1997). Inducing lifestyle regularity in recovering bipolar disorder patients: Results from the maintenance therapies in bipolar disorder protocol. Biological Psychiatric, 42(12), 1165-1173. doi:10.1016/ s0006-3223(96)00241-7

Franklin, T. B., Saab, B. J., \& Mansuy, I. M. (2012). Neural mechanisms of stress resilience and vulnerability. Neuron, 75, 747-761. doi:10.1016/j.neuron.2012.08.016

Fried, R. G. (2002). Nonpharmacologic treatments in psychodermatology. Dermatologic Clinics, 20(1), 177-185. doi:10.1016/ s0733-8635(03)00055-x

Gapp, K., Woldemichael, B. T., Bohacek, J., \& Mansuy, I. M. (2013). Epigenetic regulation in neurodevelopment and neurodegenerative diseases. Neuroscience. doi:10.1016/j. neuroscience.2012.11.040

Getz, L., Kirkengen, A. L., \& Ulvestad, E. (2011). The human biology - Saturated with experience. doi:10.4045/ tidsskr.10.0874. Retrieved from http:/www.ncbi.nlm. nih.gov/pubmed/21494303 [Reprinted from Tidsskr Nor Laegeforen. Journal of the Norwegian Medical Association, 131(7), 683-687].

Gray, T. S., \& Bingaman, E. W. (1996). The amygdala: Corticotropin-releasingfactor, steroids, and stress. Critical Reviews in Neurobiology, 10(2), 155-168. doi:10.1615/critrevneurobiol. v10.i2.10

Gubernick, D. J., \& Alberts, J. R. (1983). Maternal licking of young: Resource exchange and proximate controls. Physiology \& Behavior, 31, 593-601. doi:10.1016/0031-9384(85)90040-x

Gudsnuk, K. M. A., \& Champagne, F. A. (2011). Epigenetic effects of maternal care. Clinics in Perinatology, 38, 703-717. doi:10.1016/j.clp.2011.08.005

Guegan, T., Cutando, L., Ayuso, E., Santini, E., Fisone, G., Bosch, F., ...Martin, M. (2013). Operant behavior to obtain palatable food modifies neuronal plasticity in the brain reward circuit. European Neuropsycholopharmacology, 23, 146-159. doi:10.1016/j.euroneuro.2012.04.004

Herrera, B. M., Keildson, S., \& Lindgren, C. M. (2011). Genetics and epigenetics of obesity. Maturitas, 69, 41-49. doi:10.1016/j.maturitas.2011.02.018

Herman, J. P., \& Cullinan, W. E. (1997). Neurocirtuitry of stress: Central control of the hypothalamo-pituitary-adrenocortical axis. Trends in Neuroscience, 20, 297-310. doi:10.1016/ s0166-2236(96)10069-2 
Higley, J., Haser, M. F., Suomi, S. J., \& Linnoila, M. (1991) Nonhuman primate model of alcohol abuse: Effects of early experience, personality, and stress on alcohol consumption. Proceedings of the National Academy of Sciences of the USA, 88, 7261-7265. doi:10.1073/pnas.88.16.7261

Holmes, A., Guisquet, A. M., Vogel, E., Millstein, R. A., Leman, S., \& Belzung, C. (2005). Early life genetic, epigenetic and environmental factors shaping emotionality in rodents. Neuroscience and Biobehavioral Reviews, 29, 1335-1346. doi:10.1016/j.neubiorev.2005.04.012

Hugoson, A., Ljunquist, B., \& Brevik, T. (2002). The relationship of some negative events and psychological factors to periodontal disease in adult Swedish population 50 to 80 years of age. Journal of Clinical Periodontology, 29, 247-253. doi:10.1034/j.1600-051x.2002.290311.x

Huot, R. L., Gonzalez, M. E., Ladd, C. O., Thrivikraman, K. V., \& Plotsky, P. M. (2004). Foster litters prevent hypothalamicpituitary-adrenal axis sensitization mediated by neonatal maternal separation. Psychoneuroendocrinology, 29, 279-289. doi:10.1016/s0306-4530(03)00028-3

Hyman, S. E. (2009). How adversity gets under the skin. Nature Neuroscience, 25(3), 241-244. doi:10.1038/nn0309-241

Jewell, D. S., \& Mylander, M. (1988). The psychology of stress: Run silent, run deep. In G. P. Chrousos, D. L. Loriaux, \& P. W. Gold (Eds.), Mechanisms of physical and emotional stress (pp. 489-505). New York: Plenum. doi:10.1007/9781-4899-2064-5_37

Jones, P. A., \& Taylor, S. M. (1980). Cellular differentiation, cytidine analogs and DNA methylation. Cell, 20(1), 85-93. doi:10.1016/0092-8674(80)90237-8

Kaplan, L. A., Evans, L., \& Monk, C. (2008). Effects of mothers' prenatal psychiatric status and postnatal caregiving on infant biobehavioral regulation: Can prenatal programming be modified? Early Human Development, 84(4), 249-256. doi:10.1016/j.earlhumdev.2007.06.004

Kennedy, C. H., Thompson, T., \& Caruso, M. (2001). Experimental analyses of gene-brain-behavior relations. Journal of Applied Behavior Analysis, 34, 539-549. doi:10.1901/ jaba.2001.34-539

Koegler-Muly, S. M., Owens, M. J., Ervin, G. N., Kilts, C. D., \& Nemeroff, C. B. (1993). Potential corticotropin-releasing factor pathways in the rat brain as determined by bilateral electrolytic lesions of the central amygdaloid nucleus and paraventricular nucleus of the hypothalamus. Journal of Neuroendocrinology, 5, 95-98. doi:10.1111/j.1365-2826.1993. tb00367.x

Lavicky, J., \& Dunn, A. J. (1993). Corticotropin-releasing factor stimulates catecholamine release in hypothalamus and pre-frontal cortex in freely moving rats as assessed by microdialysis. Journal of Neurochemistry, 60, 602-612. doi:10.1111/j.1471-4159.1993.tb03191.x

Lazarus, R. S., \& Lazarus, B. N. (1994). Passion and reason. New York: Oxford University Press.

Le Dantec, F. (1903). Traité de biologie. Paris: Félix Alcan.

Lee, P. R., Brady, D. L., Shapiro, R. A., Dorsa, D. M., \& Koenig, J. L. (2007). Prenatal stress generates deficits in rat social behavior. Brain Research, 1156, 152-167. doi:10.1016/j. brainres.2007.04.042

Levine, S. (2000). Influence of psychological variables on the activity of the hypothalamic-pituitary-adrenal axis. European Journal of Pharmacology, 405, 149-160. doi:10.1016/s00142999(00)00548-3
Li, L., \& Tang, B. L. (2005). Environmental enrichment and neurodegenerative diseases. Biochemical and Biophysical Research Communications, 334, 293-297. doi:10.1016/j. bbrc.2005.05.162

Luthar, S., \& Ziegler, E. (1991).Vulnerability and comperency: A review of research on resiliense and childhood. The American Journal of Ortopsychiatry, 61, 6-22. doi:10.1037/h0079218

Lyons, D. M., Buckmaster, P. S., Lee, A. G., Wu, C., Mitra, R., Duffey, L. M., ...Schatzberg, A. F. (2010). Stress coping stimulates hippocampal neurogenesis in adult monkeys. Proceedings of the National Academy of Sciences of the USA, 107, 14823-14827. doi:10.1073/pnas.0914568107

Lyons, D. M., Yang, C., Mobley, B. W., Nickerson, J. T., \&Schatzberg, A. F. (2000). Early environmental regulation of glucocorticoid feedback sensitivity in young adult monkeys. Journal of Neuroendocrinology, 12, 723-728. doi:10.1046/j.1365-2826.2000.00505.x

McEwen, B. S. (2008). Understanding the potency of stressful early life experiences on brain and body function. Metabolism Clinical and Experimental, 57(2), 11-15. doi:10.1016/j. metabol.2008.07.006

McEwen, B. S., \& Getz, L. (2013). Lifetime experiences, the brain and personalized medicine: An integrative perspective Metabolism Clinical and Experimental, 62(Suppl. 1), S20S26. doi:10.1016/j.metabol.2012.08.020

McGowan, P. O., Sasaki, A., Alessio, A. C. D., Dymov, S., Labonté, B., Szyf, M., ...Meaney, M. (2009). Epigenetic regulation of the glucocorticoid receptor in human brain associates with childhood abuse. Nature Neuroscience, 12, 342-349. doi:10.1038/nn.2270

McLaughlin, K. A., Nelson, C. A., Fox, N. A., \& Zeanah, C. H. (2012). Attachment security as a mechanism linking foster care placement with improved mental health outcomes in previously institutionalized children. Journal of Child Psychology and Psychiatry, 53, 46-55. doi:10.1111/j.14697610.2011.02437.x

Meaney, M. J. (2001). Maternal care, gene expression, and the transmission of individual differences in stress reactivity across generations. Annual Review of Neuroscience, 24, 11611192. doi:10.1146/annurev.neuro.24.1.1161

Meaney, M. J., Diorio, J., Widdowson, J., LaPlante, P., Caldji, C., Seckl, J. R., \& Plotsky P. M. (1996). Early environmental regulation of forebrain glucocorticoid receptor gene expression: Implications for adrenocortical responses to stress. Seminars in Neuroscience, 18, 49-72. doi:10.1159/000111396

Muhammad, A., \& Kolb, B. (2011). Maternal separation altered behavior and neuronal spine density. Behavioral Brain Research, 223, 7-16. doi:10.1016/j.bbr.2011.04.015

Newlin, D. B., \& Levenson, R. W. (1982). Cardiovascular responses of individual with type a behavior pattern and parental coronary heart disease. Journal of Psychosomatic Research, 26, 393-402. doi:10.1016/0022-3999(82)90013-7

Piaget, J. (1970). Epistemologia genética. Petrópolis, RJ: Vozes. Rabin, D. S., Schmidt, P. J., Campbell, G., Gold, P. W., Jensvold, M., \& Rubinow, D. R. (1990). Hypothalamic-pituitary-adrenal function in patients with the premenstrual syndrome. The Journal of Clinical Endocrinoogy \& Metabolism, 71, 11581162. doi:10.1210/jcem-71-5-1158

Rangé, B. (2001). Psicoterapias cognitivo-comportmentais: Um diálogo com a psiquiatria. Porto Alegre, RS: Artmed.

Razin, A. (1998). CpG methylation chromatin structure and gene silencing: A three-way connection. EMBO Journal, 17, 4905-4908. doi:10.1093/emboj/17.17.4905 
Noro, G. \& Gon, M. C. C. (2015). Epigenética, Cuidados Maternais e Vulnerabilidade ao Estresse: Conceitos Básicos e Aplicabilidade.

Ros-Simó, C., \& Valverde, O. (2012). Early-life social experiences in mice affect emotional behaviour and hypothalamicpituitary-adrenal axis function. Pharmacology, Biochemistry and Behavior, 102, 434-441. doi:10.1016/j.pbb.2012.06.001

Salposky, R. M. (2000). How do glucocorticoids influence stress responses? Integrating permissive, suppressive, stimulatory and preparative actions. Endocrine Reviews, 21, 55-89. doi:10.1210/er.21.1.55

Seckl, J. R., \& Meaney, M. J. (1994). Early life events and later development of ischaemic heart disease. Lancet, 342, 1236 doi:10.1016/0140-6736(93)92215-f

Selye, H. (1959). Stress, a tensão da vida. São Paulo, SP: Instituição Brasileira de Difusão Cultural.

Skinner, B. F. (1989). Questões recentes na análise comportamental. Campinas, SP: Papirus.

Souza, E. A. P. (1996). Incidência de stress no período pré-menstrual em mulheres com epilepsia. In M. Lipp (Ed.), Pesquisas sobre stress no Brasil (pp. 109-128). Campinas, SP: Papirus.

Stahl, S. M. (2012). Psychotherapy as an epigenetic 'drug': Psychiatric therapeutics target symptoms linked to malfunctioning brain circuits with psychotherapy as well as with drugs. Journal of Clinical Pharmacy and Therapeutics, 37(3), 249-253. doi:10.1111/j.1365-2710.2011.01301.x

Turner, B. (2001). Chromatin and gene regulation. Oxford, UK: Blackwell Science. doi:10.1002/9780470750629

Valentino, R. J., Curtis, A. L., Page, M. E., Pavcovich, L. A., \& Florin-Lechner, S. M. (1998). Activation of the locus ceruleus brain noradrenergic system during stress: Circuitry, consequences, and regulation. Advances in Pharmacology, 42, 781-784. doi:10.1016/s1054-3589(08)60863-7

Von, H. L. C. (2002). Maternal stress and T-cell differentiation of the developing imune system implications for the development of asthma and atopy. Journal of Allergy and Clinical Immunology, 109(6), 923-928. doi:10.1067/mai.2002.124776

Weaver, I. C., Cervoni, N., Champagne, F. A., D’Alessio, A. C., Sharma, S., Seckl, J. R., ...Meaney, M. J. (2004). Epigenetic programming by maternal behavior. Nature Neuroscience, 7 , 847-854. doi:10.1038/nn1276

Weiss, I. C., Pryce, C. R., Jongen-Relo, A. L., Nanz-Bahr, N. I., \& Feldon, J. (2004). Effect of social isolation on stress-related behavioural and neuroendocrine state in the rat, Behavioral Brain Research, 152, 279-295. doi:10.1016/j.bbr.2003.10.015 